\title{
Confirmation bias: A barrier to community policing
}

\author{
Michael D. Schlosser, ${ }^{\star}$ Jennifer K. Robbennolt, ${ }^{\dagger}$ Daniel M. Blumberg, ${ }^{\ddagger}$ and Konstantinos Papazoglou $\S$
}

\begin{abstract}
This is a very challenging time for police-community relations, one characterized by a mutual lack of trust between police and citizens. But trust is an important tenet of effective community policing. Trust between police and communities can result in better problem solving, fewer legal violations by citizens, less frequent use of force by the police, less resistance by citizens during arrests, greater willingness to share information, less inclination to riot, and greater willingness of community members and police to cooperate. One key obstacle to fostering trust between the community and police is confirmation bias-the tendency for people to take in information and process it in a way that confirms their current preconceptions, attitudes, and beliefs. Recognizing and add ressing confirmation bias, therefore, plays a critical role in fostering more productive engagement. If we are to improve police-community relations and co-create a way forward, learning to approach debates with open minds, an awareness of the lens of our own perspectives, commitment to considering the opposite, and the goal of listening with curiosity are essential.
\end{abstract}

Key Words Police-community relations; police; trust.

\section{INTRODUCTION}

This is a challenging time for police-community relations. Citizens and police officers lack trust in each other (Pew Research Center, 2020). Trust-building through community policing has been hampered by a global pandemic (Montgomery, 2020). And trust has been undermined by highly publicized incidents in which officers have used deadly force on black and brown men and women.

These use-of-force incidents have become flashpoints in police-community relations. Although most arrests are made without using force, many prominent use-of-force incidents have involved the use of deadly force, including some in which the use of force was unlawful. At the extremes, citizens and police officers may agree that a particular use of force was appropriate or inappropriate, lawful or unlawful. However, in many cases citizens and police officers view these incidents quite differently. On the one hand, officers tend to justify the use of force by focusing on the possible risks of not using force. Citizens, by contrast, see the same use of force as excessive and unnecessary. These strong and opposing views contribute to an "us against them" mentality.

It is critical for citizens and law enforcement to develop mutual trust so that they can work together to identify needs, reduce crime, solve community problems, and enhance quality of life. While such "community policing" initiatives are vital, basic differences in how events are understood can make it difficult for the community and police to work together. Indeed, the divergent and often strongly held understandings, beliefs, and attitudes of police officers and community members create obstacles to advancing the goals of community policing. Understanding the ways in which "confirmation bias" influences our perceptions and interpretations of what we experience can help us make progress in this regard.

\section{What is Confirmation Bias?}

Confirmation bias is the tendency for people to receive information and process it in a way that confirms their current preconceptions, attitudes, and beliefs (Nickerson, 1998). We seek out, pay closer attention to, and better remember information consistent with our own preferences and beliefs. By contrast, we tend to avoid, discount, and forget information that challenges those beliefs and preferences (Klayman \& $\mathrm{Ha}, 1987)$. When information is ambiguous, we are adept at interpreting it in ways that concur with our preconceptions, attitudes, and beliefs. These processes are an inherent and often unconscious part of our human cognition.

Correspondence to: Michael D. Schlosser, Ph.D., Director, University of Illinois Police Training Institute, Champaign, IL 61820, USA. E-mail: schlossr@illinois.edu

To cite: Schlosser, M. D., Robbennolt, J. K., Blumberg, D. M., \& Papazolglou, K. (2021). Confirmation bias: A barrier to community policing. Journal of Community Safety and Well-Being, 6(4), 162-167. https://doi.org/10.35502/jcswb.219

(C) Author(s) 2021. Open Access. This work is distributed under the Creative Commons BY-NC-ND license. For commercial re-use, please contact sales@sgpublishing.ca. gPUBLISHING Published by SG Publishing Inc. CSA Official publication of the Community Safety Knowledge Alliance. 
Take an example that most of us have experiencedwatching sports. A classic study asked students from rival schools to watch a video of a football game between their teams and make a variety of assessments. Although students watched the same game, their evaluations of the behaviour of the players and officiating depended on which school they attended. Students' perceptions and interpretations of the action on the field were influenced by their pre-existing preferences and loyalties (Hastorf \& Cantril, 1954).

In this example, preferences based on team loyalty influenced the way fans of opposing teams understood what happened on the field. However, our beliefs, attitudes, and preferences are wide ranging. We each carry with us a set of assumptions and stereotypes about race or ethnicity, gender, age, occupation, sexual orientation, how someone speaks or dresses, what sports team they like, and so on. These assumptions can help us rapidly process a great deal of information and make decisions quickly, but they influence our judgments in other ways as well. Each of us also has our own mix of preferences and hopes and we have each had different experiences and developed a variety of attitudes. All these aspects of our worldview can unconsciously affect our understandings, actions, and decisions. When it comes to confirmation bias, it is these attitudes, beliefs, and preferences that we are prone to confirm and that shape the way we perceive and interpret the world.

Confirmation bias influences a range of perceptions and judgments, many of which are more directly relevant to police-community relations than how we watch football. Consider a different example. In another more tightly controlled study, people were asked to watch a video of a protest and evaluate whether the protesters were blocking access, the risk of violence, and the extent to which they were engaging in persuasion or intimidation. Half of the participants were told that the protest occurred outside an abortion clinic; the other half were told that it occurred at a campus recruitment centre to protest the military's "don't ask, don't tell" policy. Although they watched the same recording, people with different pre-existing views on these two issues interpreted the protests and protesters differently. Protest activity was judged more favourably when the purpose of the demonstration was consistent with participants' views on that issue and more negatively when the purpose of the protest conflicted with their views. In other words, people seeing the same video footage judged the risk of violence differently depending on their attitude toward the issue motivating the protest (Kahan et al., 2012).

Similar findings come from research that explores how people perceive and interpret video evidence of interactions between police officers and citizens. How people assess the interaction and their judgments about the officer are influenced by their prior attitudes towards the police (Granot et al., 2014), stereotypes (Salerno \& Sanchez, 2020), and other attitudes and beliefs (Jones et al., 2017; see also Granot et al., 2018). Police officers are inclined to look for circumstances to justify the use of force, emphasize the risks of not using force, and focus on the moment at which force was used. Citizens, by contrast, typically focus on how force could have been avoided and on the interactions leading up to the point at which force was used. In addition, police officers are more likely to focus on whether the use of force was legal, whereas citizens' judgments of legitimacy draw on perceptions that go beyond the question of legality (Celestin \& Kruschke, 2019; Meares et al., 2015).

Other studies have shown that confirmation bias can influence the trajectory of a police investigation (Charman et al., 2017; O'Brien, 2009), the ways in which suspects are interrogated (Hill et al., 2008; Kassin et al., 2003; Lidén et al., 2018; Narchet et al., 2010), and how jurors and judges make decisions (Goodman-Delahunty et al., 1998; Lidén et al., 2019). In addition, we tend to pay more attention to and find more credibility in news and research that support the things that we believe and want to be true, while downplaying information that opposes our worldview (Lord et al., 1979).

One aspect of confirmation bias that can make it particularly harmful to good relations is that, although it is a human phenomenon and has a pervasive influence on perceptions and judgments, it is hard to realize that it is happening. It feels as if we are experiencing the world as it is-that our perceptions are objective (Ross \& Ward, 1996). These feelings of objectivity make it difficult to appreciate that what we see and experience is significantly influenced by our perspective. Indeed, we each experience a "bias blind spot," typically finding it easier to recognize these sorts of influences on other people's thinking and judgment than on our own (Pronin et al., 2004).

\section{Confirmation Bias and Community Policing}

Various forms of community policing have long been adopted in the United States and other countries. The terms used to describe this set of practices, including police-community relations, community-oriented policing, and simply community policing, have varied over time. But no matter the name, community policing practices reflect the need for the police to work with the community to not only prevent and solve crimes, but also improve the quality of life for everyone in their jurisdictions. As the President's Task Force on 21st Century Policing (2015, p. 45) puts it, law enforcement and communities need to "co-produce public safety."

Community policing is both a philosophy and a set of real actions. The Office of Community Oriented Policing Services (2003, p. 2) defines community policing as "a philosophy that promotes organizational strategies that support the systematic use of partnerships and problem-solving techniques to proactively address the immediate conditions that give rise to public safety issues such as crime, social disorder, and fear of crime." According to Lawrence and McCarthy (2013), the three essential components of community policing are organizational transformation, community partnerships, and problem solving. Community policing requires officers and citizens to be willing to meet, discuss issues, and collaborate to solve community problems, with police officers at all levels (Administrative, Command, Sergeants, and Patrol Officers) developing relationships and collaborating with community members and community organizations (e.g., local governments, schools, churches, businesses, social service agencies).

An essential aspect of community policing is trust: citizens trusting the police and the police trusting citizens. Developing trusting relationships makes both citizens and officers safer (Tyler et al., 2015). A trusting relationship between the police and community can mean fewer legal violations by citizens, less frequent use of force by the police, less resistance 
by citizens during arrests, greater willingness to share information, less inclination to riot, and greater willingness of community members and police to cooperate (Tyler et al., 2015).

Confirmation bias can undermine the trust that is central to community policing. Different perceptions of eventswhether those events are high-profile encounters or everyday interactions-expand the gap between the police and the citizens they serve, making it difficult to work from a common understanding. Moreover, the bias blind spot makes it hard to appreciate that our own perceptions are influenced by our worldviews. Because we each feel like we are experiencing the world objectively, it is hard to imagine that a reasonable person could see the same events so differently. It is then easy to conclude that someone who does not see the same facts is blind, biased, unreasonable, or worse. Research has found that when others disagree with us, we tend to conclude that they are biased (Kennedy \& Pronin, 2008).

Both sides, therefore, conclude that the other side is biased and fail to recognize the influences of confirmation bias on their own thinking. This can lead each side to see the differences as wider than they are, the conflict as more extensive, and cooperation as likely to be less productive. It can also lead both sides to treat each other in ways unlikely to lead to finding common ground. The result can be a downward spiral (Kennedy \& Pronin, 2008; Robinson et al., 1995). These patterns interfere with productive conversations and the kind of police-community engagement central to community policing efforts.

\section{Addressing Confirmation Bias}

How can police officers and community members address the effects of confirmation bias in ways that foster more productive engagement? First, data and video footage can be helpful because they can place important limits on the range of interpretations that can be drawn. Think back to the football fans who "saw" different games. While they made different judgments about things like which team was responsible for the rough play, whether the nature of the play was unsportsmanlike, and the number of rule violations, few observers from either team thought that the game was "clean and fair," and they did see their own team commit at least some rule violations (Hastorf \& Cantril, 1954). What actually happened in the game influenced their perceptions and limited the possible interpretations.

The less ambiguous the situation, the less room there is for divergent interpretation or justification (Hsee, 1996). Similarly, the more robust the research base, the less likely that research will be interpreted in different ways. As MacCoun (1998, p. 281) notes, few people "see whatever they want in the data. The available evidence constrains our interpretations... and the stronger and more comprehensive the evidence, the less wiggle room available for bias."

This intuition helps explain why members of both groups may welcome body cameras. Police officers and community members may have different beliefs about what body cameras are likely to reveal. Cops may expect that the cameras will show them acting appropriately, while citizens may expect such cameras to reveal misconduct. But both groups share an expectation that the footage will reduce disagreement about what happened.
Simply presenting new data or relying on camera footage may be insufficient given that confirmation bias means that different people can look at the same research or videos and come to different conclusions. But data and camera footage place some bounds on interpretation: "People do not seem to be at liberty to conclude whatever they want to conclude merely because they want to....[P]eople motivated to arrive at a particular conclusion attempt to be rational and to construct a justification of their desired conclusion that would persuade a dispassionate observer. They draw the desired conclusion only if they can muster up the evidence necessary to support it" (Kunda, 1990, pp.482-483). When a more robustbody of evidence is available, understandings are more likely to converge.

Second, research has also found that one way to reduce the effect of confirmation bias is to explicitly "consider the opposite" (Kray \& Galinsky, 2003; Lord et al., 1984). In other words, it is useful to consciously reflect on what a situation would look like from another vantage point, to deliberately look for aspects of a situation that could be interpreted differently, to look for evidence inconsistent with one's hopes or expectations, and to consider how one would evaluate the quality of a research study if it had come to the opposite conclusion. These sorts of active strategies are more effective at reducing reliance on preconceptions than simply trying to "be unbiased." Recognizing that our perspective influences our perceptions and that the bias blind spot clouds our ability to see our own biases can help motivate this active search for broader insights.

Third, and relatedly, this process of considering the opposite is likely to be the most effective when departmental culture supports disclosure and is open to acknowledging error, and when members of the police and community engage with each other, exchange information about their perspectives, and actively listen (Eyal et al., 2018). When people feel misunderstood, it is hard to work together. But when people feel that their perspective is understood by the other side, increased trust and more positive intentions towards each other are more likely (Livingstone et al., 2020). Listening also tends to lead to more listening on the other side and makes it more possible to grapple with complexity (Itzchakov et al., 2017). This highlights the importance of engaging from a curiosity-oriented stance directed at learning more about each other's contrasting perspectives, even if the two groups ultimately continue to see things differently.

\section{The Role of Law Enforcement}

Police leaders committed to improving relations with the community must understand and address confirmation bias. A first step is to understand why confirmation bias exists and how it can impact officers' performance. As is the case for members of all professions, career is often central to police officers' identity. When the issues involved are closely connected with one's self-concept in this way, confirmation bias is even more likely to occur (Kunda, 1990; Sharot, 2017). This is because it can be difficult to simultaneously maintain a positive self-concept as a member of a profession sworn to serve and protect the community and recognize that fellow officers or practices of the profession have caused harm to the community or the profession (Tavris \& Aronson, 2020).

Because the police occupy a position of authority, they bear the weight of responsibility for developing and maintaining 
good relations with the community. Training in the academy, mandated continuing education classes, and police news outlets all present opportunities for helping officers understand how their perspectives influence their perceptions, how confirmation bias interferes with good policing and contributes to a lack of trust, and how to take steps to recognize and address these influences.

Police leaders can adopt specific strategies to address confirmation bias. This should begin in the recruiting and hiring phase, with greater attention paid to the breadth of experiences of job applicants. The narrower an individual's pre-existing beliefs and experiences, the more likely he or she is to take a narrow view of new information. Agencies, therefore, should seek to hire applicants with wide-ranging experiences. Background investigation, for example, could identify evidence of diversity in applicants' friendships, work experiences, and group memberships or affiliations (Blumberg et al., 2014); a demonstrable willingness to engage with and maintain broad networks across race and ethnicity, gender, nationality, religion, disability, or sexual orientation; and a sense of curiosity. In California, a 2020 bill was signed into law that directs every law enforcement agency to "review the job description that is used in the recruitment and hiring of those peace officers and...make changes that emphasize community-based policing, familiarization between law enforcement and community residents, and collaborative problem solving, while de-emphasizing the paramilitary aspects of the job" (California Legislative Information, 2020, para. 13651). Leaders from agencies nationally should consider ways to adopt these guidelines. One unintended benefit of this approach may be to reduce the negative impact of confirmation bias among newly hired police officers.

Law enforcement agencies can also take steps to address confirmation bias during training. As agencies incorporate initiatives to improve policing practices and police-community relations, such as increased transparency and accountability, use-of-force policies, de-escalation training, implicit bias awareness, cultural competency benchmarks, and procedural justice (Quattlebaum et al., 2018), greater attention needs to be paid to training officers in ways that reinforce these principles and the ways in which traditional training fosters some of the problems police leaders are trying to correct (Blumberg et al., 2020). With regard to confirmation bias, officers can be taught to recognize that things are not always the way they initially appear and should practice testing their assumptions about the reasons underlying someone's behaviour or demeanor during an encounter. Training can focus on producing independent thinkers and creative problem-solvers by "increas(ing) opportunities for recruits' autonomous decision-making" (Blumberg et al., 2019, p. 5). Building skills associated with mental flexibility and the ability to recognize and adapt to ambiguity can increase recruits' capacity to consider alternative perspectives and interpretations.

In addition to training that makes police officers aware of the ways in which confirmation bias can impact their own perceptions and behaviour, it is critical for officers to be aware that community members will come into encounters with law enforcement with their own existing perspectives, including a range of different experiences with and expectations about law enforcement. These experiences and expectations can shape citizens' behaviour for reasons that may not be transparent to the officers. Considering alternative explanations for and testing assumptions about such behaviour is important. In addition, when an officer's demeanor, body language, tone of voice, and actions reinforce negative expectations, situations can escalate quickly. In addition to teaching de-escalation and non-escalation skills, training and supervision must focus on ways in which officers can build and reinforce positive, rather than negative, public expectations. Other promising philosophies and training include procedural justice and fair and impartial policing.

Implementing trauma-informed practice that "realizes the widespread impact of trauma and understands potential paths for recovery; recognizes the signs and symptoms of trauma in clients, families, staff, and others involved with the system; and responds by fully integrating knowledge about trauma into policies, procedures, and practices, and seeks to actively resist re-traumatization" (SAMHSA, 2014, p. 9) would fundamentally alter the way in which police officers think about and interact with members of the community. A trauma-informed approach is service-oriented and compassionate and encourages officers to consider (and ask) "what has happened to you?" rather than approaching community members with the mindset of "what's wrong with you?" (Blumberg et al., 2020, p. 9). Officers with a traumainformed mindset approach members of the community, including victims, perpetrators, and witnesses, in a respectful, compassionate manner, appreciating that part of their responsibility is to do what they can to avoid traumatizing or re-traumatizing others. Effectively teaching and implementing practices like this can expand the ways in which officers and community members see each other and decrease the negative bases for confirmation bias.

\section{CONCLUSION}

It is imperative that law enforcement agencies collaborate with scholars, policy makers, and community members to develop comprehensive training programs that address confirmation bias in police work. To this end, the training of police recruits, early career police officers, and administrators should make clear that police work is not just about fighting crime or using force. Instilling a sense of the nuanced contexts of policing and the broad range of circumstances that officers may encounter can provide a broader base of expectations and beliefs in which to root interpretation and decisions. Failing to clearly provide this perspective early in police careers risks interpretation and decisions that are more likely to confirm more narrow and unfounded assumptions. An ongoing organizational environment that supports and reinforces this perspective is also essential.

Law enforcement researchers should further explore the circumstances and expectations that ground confirmation bias in policing. More nuanced exploration of how factors such as a citizen's racial or ethnic cultural background influence officers' perceptions, interpretations, reactions, and decision-making through confirmation bias is important. The circumstances in which confirmation bias may be less likely to occur should also be explored. It would furthermore be valuable to explore differences in the bases for and operation of confirmation bias among officers from different cultural backgrounds. In addition, research should explore how evidence-based training 
programs might best help officers address confirmation bias, hence minimizing the likelihood that pre-existing attitudes and expectations will interfere with their decision-making in the line of duty or broadening the base of expectations on which they can draw. Studies that explore all of these issues will help inform strategies for addressing and mitigating confirmation bias as part of police work.

Recognizing and addressing confirmation bias is only one step in a much larger process of reform. But it is a step that can help pave the way to a better understanding, increased trust, and more effective collaboration. Confirmation bias is deeply embedded in all of us. If we are to improve police-community relations and co-create a way forward, learning to approach these debates with open minds, an awareness of the lens of our own perspective, a commitment to consider the opposite, and the goal of listening with curiosity are essential.

\section{CONFLICT OF INTEREST DISCLOSURES}

The authors declare that there are no conflicts of interest.

\section{AUTHOR AFFILIATIONS}

*University of Illinois Police Training Institute, Champaign, IL, 671820, USA; ${ }^{\dagger}$ College of Law, University of Illinois, Champaign, IL, USA; ${ }^{\ddagger}$ The POWER Project, San Diego, CA, USA; ${ }^{\circledR}$ Clinical, Police, \& Forensic Psychologist, The POWER Project, San Diego, CA, USA; ProWellness Inc., Toronto, ON, Canada.

\section{REFERENCES}

Blumberg, D. M., Griffin, D., \& Jones, O. K. (2014). Improving police officer hiring decisions: An integrated organizational approach. Organizational Cultures: An International Journal, 13, 1-19.

Blumberg, D. M., Papazoglou, K., \& Schlosser, M. D. (2020). Organizational solutions to the moral risks of policing. International Journal of Environmental Research and Public Health, 17(20), 7461. https:// doi.org.10.3390/ijerph17207461

Blumberg, D. M., Schlosser, M. D., Papazoglou, K., Creighton, S., \& Kaye, C. (2019). New directions in police academy training: A call to action. International Journal of Environmental Research and Public Health, 16(24), 4941. https://doi.org.10.3390/ijerph16244941.

California Legislative Information. Assembly Bill No. 84. Chapter 16. An act to amend Sections 22950.6 and 22955.1 of the Education Code, to amend Sections 19827, 19849, 19851, 20825.1, and 20825.2 of, and to add Section 20825.12 to, the Government Code, and to amend Section 11873 of the Insurance Code, relating to public employment and retirement, and making an appropriation therefor, to take effect immediately, bill related to the budget. https://leginfo.legislature.ca.gov/faces/billTextClient.xhtml? bill_ $\mathrm{id}=201920200 \mathrm{AB} 846$

Celestin, B. D., \& Kruschke, J. K. (2019). Lay evaluations of police and civilian use of force: Action severity scales. Law and Human Behaviour, 43(3), 290-305. https://doi.org/10.1037//hb0000333

Charman, S. D., Kavetski, M., \& Mueller, D. H. (2017). Cognitive bias in the legal system: Police officers evaluate ambiguous evidence in a belief-consistent manner. Journal of Applied Research in Memory and Cognition, 6(2), 193-202. https://doi.org/10.1016/i.jarmac. 2017.02.001

Eyal, T., Steffel, M., \& Epley, N. (2018). Perspective mistaking: Accurately understanding the mind of another requires getting perspective, not taking perspective. Journal of Personality and Social Psychology, 114(4), 547.

Goodman-Delahunty, J., Greene, E., \&Hsiao, W. (1998). Construing motive in videotaped killings: The role of jurors' attitudes toward the death penalty. Law and Human Behavior, 22, 257-271.
Granot, Y., Balcetis, E., Schneider, K. E., \& Tyler, T. R. (2014). Justice is not blind: Visual attention exaggerates effects of group identification on legal punishment. Journal of Experimental Psychology: General, 143(6), 2196.

Granot, Y., Balcetis, E., Feigenson, N., \& Tyler, T. (2018). In the eyes of the law: Perception versus reality in appraisals of video evidence. Psychology, Public Policy, and Law, 24(1), 93.

Hastorf, A. H., \& Cantril, H. (1954). They saw a game-a case study. The Journal of Abnormal and Social Psychology, 49(1), 129.

Hill, C., Memon, A., \& McGeorge, P. (2008). The role of confirmation bias in suspect interviews: A systematic evaluation. Legal and Criminological Psychology, 13(2), 357-371.

Hsee, C. K. (1996). Elastic justification: How unjustifiable factors influence judgments. Organizational Behavior and Human Decision Processes, $66(1), 122-129$.

Itzchakov, G., Kluger, A. N., \& Castro, D. R. (2017). I am aware of my inconsistencies but can tolerate them: The effect of high-quality listening on speakers' attitude ambivalence. Personality and Social Psychology Bulletin, 43(1), 105-120.

Jones, K. A., Crozier, W. E., \& Strange, D. (2017). Believing is seeing: Biased viewing of body-worn camera footage. Journal of Applied Research in Memory and Cognition, 6(4), 460-474.

Kahan, D. M., Hoffman, D. A., Braman, D., \& Evans, D. (2012). They saw a protest: Cognitive illiberalism and the speech-conduct distinction. Stanford Law Review, 64, 851.

Kassin, S. M., Goldstein, C. C., \& Savitsky, K. (2003). Behavioral confirmation in the interrogation room: On the dangers of presuming guilt. Law and Human Behavior, 27(2), 187-203.

Kennedy, K. A., \& Pronin, E. (2008). When disagreement gets ugly: Perceptions of bias and the escalation of conflict. Personality and Social Psychology Bulletin, 34(6), 833-848.

Klayman, J., \& Ha, Y. W. (1987). Confirmation, disconfirmation, and information in hypothesis testing. Psychological Review, 94(2), 211

Kray, L. J., \& Galinsky, A. D. (2003). The debiasing effect of counterfactual mind-sets: Increasing the search for disconfirmatory information in group decisions. Organizational Behavior and Human Decision Processes, 91(1), 69-81.

Kunda, Z. (1990). The case for motivated reasoning. Psychological bulletin, 108(3), 480-498.

Lawrence, S., \& McCarthy, B. (2013). What works in community policing? A best practices context for measure Y efforts. The Chief Justice Earl Warren Institute on Law and Social Policy. Retrieved January 25, 2019 from https://www.law.berkeley.edu/files/What_Works_in_Community_ Policing.pdf

Lidén, M., Gräns, M., \& Juslin, P. (2018). The presumption of guilt in suspect interrogations: Apprehension as a trigger of confirmation bias and debiasing techniques. Law and Human Behavior, 42(4), 336-354. https://doi.org/10.1037//hb0000287.supp (Supplemental)

Lidén, M., Gräns, M., \& Juslin, P. (2019). "Guilty, no doubt": Detention provoking confirmation bias in judges' guilt assessments and debiasing techniques. Psychology, Crime, and Law, 25, 219-247.

Livingstone, A. G., Rodriquez, L. F., \& Rothers, A. (2020). "They just don't understand us": The role of felt understanding in intergroup relations. Journal of Personality and Social Psychology, 119, 633-656.

Lord, C. G., Lepper, M. R., \& Preston, E. (1984). Considering the opposite: A corrective strategy for social judgment. Journal of Personality and Social Psychology, 47(6), 1231.

Lord, C. G., Ross, L., \& Lepper, M. R. (1979). Biased assimilation and attitude polarization: The effects of prior theories on subsequently considered evidence. Journal of Personality and Social Psychology, $37(11), 2098$ 
MacCoun, R. J. (1998). Biases in the interpretation and use of research results. Annual Review of Psychology, 49(1), 259-287.

Meares, T. L., Tyler, T. R., \& Gardener, J. (2015). Lawful or fair-how cops and laypeople perceive good policing. Journal of Criminal Law and Criminology, 105, 297.

Montgomery, D. (2020, October 1). COVID-19 Curbs Community Policing at a Time of Diminishing Trust. The Pew Charitable Trusts. https:// www. pewtrusts.org/en/research-and-analysis/blogs/stateline/ 2020/10/01/covid-19-curbs-community-policing-at-a-time-ofdiminishing-trust

Narchet, F., Meissner, C. A., \& Russano, M. B. (2010). Modeling the influence of investigator bias on the elicitation of true and false confessions. Law and Human Behavior, 35, 452-465.

Nickerson, R. S. (1998). Confirmation bias: A ubiquitous phenomenon in many guises. Review of General Psychology, 2(2), 175-220.

O'Brien, B. (2009). Prime suspect: An examination of factors that aggravate and counteract confirmation bias in criminal investigations. Psychology, Public Policy, and Law, 15(4), 315-334. https://doi.org/10.1037/ a0017881

Office of Community Oriented Policing Services. (2003). Community policing defined. Washington, DC: U.S. Department of Justice.

Pew Research Center. (2020, July 9). Majority of public favors giving civilians the power to sue police officers for misconduct. https:// www.pewresearch.org/politics/2020/07/09/majority-of-publicfavors-giving-civilians-the-power-to-sue-police-officers-for-misconduct/.

President's Task Force on 21 st Century Policing. (2015). Final report of the president's task force on 21 st century policing. http://www.cops.usdoj.gov/ $\mathrm{pdf} /$ taskforce/TaskForce_FinalReport.pdf.
Pronin, E., Gilovich, T., \& Ross, L. (2004). Objectivity in the eye of the beholder: Divergent perceptions of bias in self versus others. Psychological Review, 171 (3), 781.

Quattlebaum, M., Meares, T. L., \& Tyler, T. (2018). Principles of procedurally just policing. SSRN 3179519.

Robinson, R. J., Keltner, D., Ward, A., \& Ross, L. (1995). Actual versus assumed differences in construal: "Naive realism" in intergroup perception and conflict. Journal of Personality and Social Psychology, $68(3), 404$

Ross, L., \& Ward, A. (1996). Naive realism: Implications for social conflict and misunderstanding. In T. Brown, E. Reed, \& E. Turiel (Eds.), Values and knowledge (pp. 103-135). Hillsdale, NJ: Erlbaum.

Salerno, J. M., \& Sanchez, J. (2020). Subjective interpretation of "objective" video evidence: Perceptions of male versus female police officers" use-of-force. Law and Human Behavior 44(2), 97-112. https://doi. org/10.1037//hb0000366

Sharot, T. (2017). The influential mind: What the brain reveals about our power to change others. Henry Holt and Company.

Substance Abuse and Mental Health Services Administration (SAMHSA). (2014). SAMHSA's Concept of Trauma and Guidance for a TraumaInformed Approach; HHS Publication No. (SMA) 14-4884.

Tavris, C., \& Aronson, E. (2020). Mistakes were made (but not by me): Why we justify foolish beliefs, bad decisions, and hurfful acts. Houghton Mifflin Harcourt.

Tyler, T. R., Goff, P. A., \& MacCoun, R. M. (2015). The impact of psychological science on policing in the United States: Procedural justice, legitimacy, and effective law enforcement. Psychological Science in the Public Interest, 16, 75-109. 